\title{
Hyperfractionated abdominal reirradiation for gastrointestinal malignancies
}

\author{
Andrew Hunt ${ }^{1}$, Prajnan Das², Bruce D. Minsky², Eugene J. Koay², Sunil Krishnan², Joseph M. Herman², \\ Cullen Taniguchi ${ }^{2}$, Albert Koong ${ }^{2}$, Grace L. Smith ${ }^{2}$ and Emma B. Holliday ${ }^{2 *}$
}

\begin{abstract}
Background: We sought to determine the role of abdominal reirradiation for patients presenting with recurrent or new primary gastrointestinal (Gl) malignancies. At our institution, we have established a hyperfractionated, accelerated reirradiation regimen consisting of 39 Gray (Gy) in 26 twice-daily fractions. Although this regimen is used frequently in the pelvis, we sought to determine its toxicity and efficacy for abdominal tumors.

Methods: Twenty-four patients who received abdominal reirradiation with a hyperfractionated, accelerated approach from 2000 to 2017 were identified. Overall survival (OS) and local progression-free survival (LPFS) were calculated using the Kaplan-Meier method. Several patient, tumor and treatment characteristics were evaluated on univariate analyses for association with OS and LPFS using a Cox proportional hazards model.

Results: Of the twenty-four patients identified, the majority $(n=11,46 \%)$ had pancreatic adenocarcinoma as their primary disease but also included upper $\mathrm{Gl}$ adenocarcinoma $(n=4)$, colon adenocarcinoma $(n=3)$, hepatobiliary cancers $(n=4)$ and other malignancies $(n=2)$. The majority of patients received 45-50.4Gy in 1.8Gy fractions as their initial abdominal radiation course. The median reirradiation dose was 39Gy in 26 twice-daily fractions with a minimum six hour interval. The median [interquartile range (IQR)] interval between the courses of radiotherapy was 28 [18.6-38.9] months. Only palliative reirradiation intent was associated with decreased OS. While colon adenocarcinoma primary was significantly associated with increased LPFS, the sample size was small $(n=3)$. The 1 -yr rate of LPFS was $38 \%$. The median [IQR] duration of freedom from local progression was 8 [3.8-19.2] months. The 1-year OS was 50\% and the median (IQR) OS was 14 [6.3-19.6] months. Thirteen patients (54\%) had acute side effects with one patient experiencing G3 nausea and one experiencing a G4 bleed; the remaining patients experienced G1-G2 symptoms.

Conclusion: Hyperfractionated, accelerated reirradiation to the abdomen was relatively well-tolerated but provided limited local control to recurrent or second primary abdominal malignancies. Reirradiation could play a role in treating these patients with palliative or curative intent, but alternative strategies for delivering increased biologically effective dose should be further explored.
\end{abstract}

Keywords: Reirradiation, External beam, Hyperfractionated, Abdominal, Gastrointestinal malignancies, Toxicity, Local control

\section{Background}

Given the recent advances in systemic therapy for several gastrointestinal malignancies, local recurrences (LR) can be life- and/or quality-of-life-limiting. For patients with pancreatic adenocarcinoma, LR occurs in $80 \%$ of patients within two years of curative-intent therapy, and $30 \%$ of these LR are isolated without distant metastasis

\footnotetext{
*Correspondence: ebholliday@mdanderson.org

${ }^{2}$ The University of Texas MD Anderson Cancer Center, 1515 Holcombe Blvd

Unit 97, Houston, TX 77030, USA

Full list of author information is available at the end of the article
}

(DM) [1-3]. For patients with gastric cancer, LR rates are closer to $33 \%$, although the majority of these patients also present with synchronous distant metastatic disease [4]. Younger patients and patients with larger tumor sizes are at highest risk for LR [5]. For patients with colon adenocarcinoma, LR rates are also approximately $32 \%$ following curative therapy [6].

The treatment of locally recurrent tumors in the abdomen varies depending on the specific histology, location and extend of recurrence as well as any prior treatments

(c) The Author(s). 2018 Open Access This article is distributed under the terms of the Creative Commons Attribution 4.0 International License (http://creativecommons.org/licenses/by/4.0/), which permits unrestricted use, distribution, and 
received. For pancreatic cancer recurring after resection, re-resection is favored if feasible, but radiation-based modalities are not recommended for patients who have received prior (chemo) radiation therapy [7]. Re-resection is also favored for locally recurrent gastric, colon and hepatobiliary cancers when feasible [8-10]. The need for alternative treatment strategies arises as patients are often not surgical candidates at the time of local recurrence either because of technical operability or medical comorbidity. Additionally, effective palliation of symptomatic LR occurring in patients with concomitant regional or metastatic disease. Radiation therapy is one such alternative local modality, but its utilization in the treatment of recurrent abdominal tumors has been limited by the increasing use of primary radiation in the neoadjuvant or adjuvant settings for abdominal tumors in the pancreas, stomach, colon and hepatobiliary region.

Previous studies have established the safety and efficacy of reirradiation to the head and neck, pelvis, breast, brain, breast, and lung [11-25]. However, reirradiation is not commonly used in patients with recurrent GI malignancies due to concerns of toxicity, with a cumulative radiation dose that exceeds established dose constraints. At our institution, a hyperfractionated accelerated reirradiation approach has been shown to be effective in the treatment of both recurrent rectal cancer and anal cancer [26-28]. Patients treated with reirradiation for recurrent rectal cancer using $1.5 \mathrm{~Gy}$ twice daily fractions to a total median dose of 39Gy demonstrated a 3-year freedom from local progression (FFLP) rate of $40 \%$ and a 3 -year overall survival (OS) rate of 39\% [27]. Patients who underwent reirradiation in twice $1.5 \mathrm{~Gy}$ daily fractions for recurrent anal cancer demonstrated a 3 -year FFLP of $56 \%$ and a 3 -year OS of $60 \%$ [28].

Haque et al. first demonstrated the safety and efficacy of abdominal reirradiation in patients with gastrointestinal malignancies, showing a 1-yr rate of freedom from local progression of $50 \%$ and a 1-yr rate of overall survival of $62 \%$ [29]. This initial report, however, was small $(n=13)$ [29]. Our aim with the current study was to update this initial experience and report the efficacy and toxicity associated with this hyperfractionated, accelerated reirradiation approach to recurrent or new primary tumors in the abdomen.

\section{Methods}

Between January 12000 and January 1 2017, 24 patients with gastrointestinal cancer and a prior history of radiation therapy had undergone reirradiation using a hyperfractionated, accelerated approach. The hospital records for these treatments were reviewed with the approval of the University of Texas MD Anderson Cancer Center Institutional Review Board.

\section{Reirradiation details}

Prior radiotherapy records were obtained and reviewed by the treating radiation oncologist. When available, prior radiotherapy records in Digital Imaging and Communications in Medicine (DICOM) format were obtained and a composite plan was generated with both the original and reirradiation dose-distributions, target coverage and dose to adjacent organs-at-risk (OARs).

For the purposes of planning reirradiation, all patients underwent a computed tomography (CT) simulation. Intravenous contrast was used at the discretion of the treating physician and was used more often in cases of hepatobiliary tumor location. Patients were asked to fast for three hours prior to simulation and treatment for stomach volume reproducibility. Abdominal compression was not used. Gross tumor volume (GTV), defined as the primary tumor and any malignant-appearing lymphadenopathy, was delineated by the treating physician based on all available diagnostic imaging. The clinical target volume (CTV) typically included the GTV plus a $1-2 \mathrm{~cm}$ margin. Elective nodal coverage was not included. The planning target volume (PTV) typically included a $5 \mathrm{~mm}$ margin for set up uncertainties with the use of daily kilovoltage image-guidance. Respiratory motion uncertainty management with either a 4DCT scan or the use of a breath hold technique was considered depending on tumor location and proximity to critical OARs. Either 3D conformal radiation therapy (3DCRT) or intensity-modulated radiation therapy (IMRT) was utilized at the discretion of the treating physician.

\section{Assessment of cancer control and toxicity endpoints}

Patients were assessed by their treating radiation oncologist at least every five fractions (twice weekly). Radiation-related toxicities were described and graded according to the Common Toxicity Criteria for Adverse Events (CTCAE), version 4.0 [30]. Acute toxicities were defined as those occurring between the initiation of radiation and six weeks after the last radiation treatment. Late toxicities were defined as those occurring and/or persisting more than 6 weeks after the last radiation treatment. All of the data collected and analyzed are retrospective in nature. Follow up was every 1-4 months for the first two years after treatment as clinically indicated at the discretion of the treating team. Dates and locations of progressive disease were recorded as well as vital status at last follow-up. Follow up information was obtained from hospital records and radiation therapy records. Follow-up information was also obtained from the MD Anderson Tumor Registry, which collects information on patients annually through letters and phone calls. 


\section{Calculation of composite maximum doses for luminal gastrointestinal organs}

For patients for whom initial radiation records and composite plans were available, the maximum point dose from the initial course, the dose from the reirradiation course and the composite dose to the stomach, duodenum, small intestine and large intestine were collected. Next, the equivalent dose in fractions for the initial course, the reirradiation course and the composite plans were calculated for each patient using the following equation:

$$
E Q D_{\mathrm{r}}^{\mathrm{f}}=D\left(\frac{d+r}{f+r}\right)
$$

Where $\mathrm{D}$ is the total dose in Gy given in d Gy fractions of $d=2$ Gy each using an $r \alpha / \beta$ ratio of 4 . As published reports of late bowel toxicity have shown the appropriate $\alpha / \beta$ ratio is $3-5$ [31-34].

\section{Statistical analysis}

Chi-square test was used for between-group comparisons of categorical variables, and the Mann-Whitney $U$ test was used for between-group comparisons of continuous variables. $P$-values $<.05$ were considered significant. Local progression-free survival (LPFS) was calculated from the initiation of reirradiation to the date of local disease progression, death from any cause or last follow-up. Overall survival (OS) was calculated from the initiation of reirradiation to the date of death from any cause or last follow-up. Analysis of LPFS and OS was performed by the Kaplan-Meier method [35]. Cox's proportional hazards model was used for univariate and multivariate analyses to evaluate potential prognostic factors for LPFS and OS. The hazard ratio (HR) is reported with the 95\% confidence interval $(\mathrm{CI})$ for each variable. Factors with a $p$-value $<.2$ on univariate analysis were included in the multivariate model. The statistical software used was JMP version 12 (SAS Institute Inc., Cary, NC).

\section{Results}

Twenty-four patients were included in our analysis with a median [interquartile range (IQR)] follow up of 16.8 [8-22.5] months.

\section{Patient characteristics}

Patient characteristics are shown in Table 1. The median [IQR] age at the time of retreatment was 65 [54.1-69.1] years. The primary cancer diagnoses were as follows: eleven patients with pancreatic adenocarcinoma, four patients with upper GI adenocarcinoma, three patients with colon adenocarcinoma, four patients with hepatobiliary cancers, and two patients with other malignancies. The majority of patients received standard fractionated radiation (1.8Gy per day) to a total dose of $45-50.4 \mathrm{~Gy}$, but one patient received $30 \mathrm{~Gy} / 24$ fractions, four patients received 30Gy/10 fractions, one patient received 30Gy/12 fractions and two patients received 35Gy/14 fractions. Twenty patients (83\%) were treated with 3DCRT and 4 patients $(17 \%)$ were treated with IMRT. The median [IQR] interval between the two treatments of radiation was 27.9 [18.6-38.9] months. Twenty-one patients (87.5\%) received concurrent chemotherapy with their first course of radiation.

At the time of reirradiation, three patients $(12.5 \%)$ had new primary tumors while 21 patients $(87.5 \%)$ had recurrent disease. All of the patients were evaluated by a surgeon at our institution and were deemed inoperable either because they had distant metastatic disease $(N=3)$, they had comorbidities that precluded surgery $(N=2)$ or they were anatomically unresectable given the location of their tumor $(N=19)$. The median [IQR] length of time between the two courses of radiation was 28 [18.6-38.9] months. The site of reirradiation was as follows: 14 patients were treated to the pancreas, five to the stomach/duodenum, two to the liver, one to mesenteric adenopathy, one to peritoneal nodules, and one to aortocaval adenopathy. Sixteen patients (66.7\%) were treated with definitive intent for local control, while eight patients (33.3\%) were treated for the palliation of tumor-related symptoms. Twelve patients (50\%) received chemotherapy prior to receiving their second radiation treatment.

All patients received accelerated, hyperfractionated reirradiation with $1.5 \mathrm{~Gy}$ delivered per fraction and two fractions delivered per day with a minimum $6 \mathrm{~h}$ interfraction interval. Seven patients received 30Gy/20 fractions, fifteen received 39Gy/26 fractions, one received $45 \mathrm{~Gy} / 30$ fractions and one patient stopped treatment early after 15Gy in 10 fractions. Fifteen patients (62.5\%) received 3DCRT with the remaining nine patients $(37.5 \%)$ receiving IMRT. Seventeen patients (70.4\%) received concurrent chemotherapy, with 14 patients receiving capecitabine, one patient receiving capecitaibine and erlotinib, one patient receiving gemcitabine and erlotinib, and one patient receiving sorafenib. The mean \pm SD gross tumor volume for patients in this series was $105.4 \pm 119.4 \mathrm{ccs}$, and the median [IQR] was 59ccs $[27.8-140 \mathrm{ccs}]$. Three patients had involved nodes treated.

\section{Patient outcomes}

The 1-year LPFS was $38 \%$, and the median [IQR] duration of freedom from local progression was 8 [3.8-19.2] months (Fig. 1). Results of univariate analyses performed for LPFS and OS are given in Table 2. Only colon adenocarcinoma primary type was significantly associated with increased LPFS, but the sample size was small $(n=3)$, with two patients not progressing and a third patient not progressing for 10 years. The 1-year OS was $50 \%$ and the median [IQR] overall survival was 14 [6.3-19.6] 
Table 1 Patient and Treatment Characteristics

\begin{tabular}{ll}
\hline Characteristic & $\begin{array}{l}\text { Median }[\mathrm{IQR}] \text { or } \\
\text { Number }(\%)\end{array}$ \\
\hline $\begin{array}{l}\text { Age at 2nd Radiation Treatment (years) } \\
\text { Sex }\end{array}$ & $65[54.1-69.1]$ \\
$\quad$ Male & $16(67 \%)$ \\
Female & $8(33 \%)$ \\
Pathology of Initial Primary & \\
Pancreatic Adenocarcinoma & $11(46 \%)$ \\
Upper Gl Adenocarcinoma & \\
Colon Adenocarcinoma & $4(16.7 \%)$ \\
Hepatobiliary Cancers $^{\mathrm{b}}$ & $3(12.5 \%)$ \\
Other $^{c}$ & $4(16.7 \%)$ \\
\end{tabular}

Dose/fractionation of 1st Radiation Treatment (total dose in Gray (Gy)/total number of fractions)

$\begin{array}{ll}30 \mathrm{~Gy} / 24 \text { fractions } & 1(4.2 \%) \\ 30 \mathrm{~Gy} / 10 \text { fractions } & 4(16.7 \%) \\ 30 \mathrm{~Gy} / 12 \text { fractions } & 1(4.2 \%) \\ 35 \mathrm{~Gy} / 14 \text { fractions } & 2(8.3 \%) \\ 45 \mathrm{~Gy} / 25 \text { fractions } & 8(33.3 \%) \\ 50.4 \mathrm{~Gy} / 28 \text { fractions } & 8(33.3 \%) \\ \text { Retreatment Interval (months) } & 27.9[18.6-38.9]\end{array}$

Type of Post-1st Radiation Disease

$\begin{array}{ll}\text { Recurrent Disease } & 21(87.5 \%) \\ \text { Second Primary Tumor } & 3(12.5 \%)\end{array}$

Location of Post-1st Radiation Disease

$\begin{array}{ll}\text { Pancreas } & 14(58.3 \%) \\ \text { Stomach/Duodenum } & 5(20.8 \%) \\ \text { Liver }^{\text {Other }} & 2(8.3 \%) \\ & 3(12.5 \%)\end{array}$

Reirradiation Intent

Definitive/Local Control $\quad 16(67 \%)$

Palliation of Bleeding $\quad 5$ (20.8\%)

Palliation of Pain $2(8.3 \%)$

Palliation of Tumor Thrombus 1 (4.2\%)

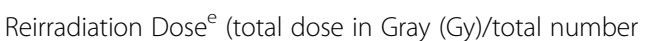
of fractions)

$\begin{array}{ll}\text { 15Gy/10 fractions } & 1(4.2 \%) \\ 30 G y / 20 \text { fractions } & 7(29.2 \%) \\ 39 G y / 26 \text { fractions } & 15(58.3 \%) \\ \text { 45Gy/30 fractions } & 1(4.2 \%) \\ \text { Reirradiation Technique } & \\ \text { 3D Conformal } & 15(62.5 \%) \\ \text { Intensity-modulated radiation therapy } & 9(37.5 \%)\end{array}$

Table 1 Patient and Treatment Characteristics (Continued)

\begin{tabular}{ll}
\hline Characteristic & $\begin{array}{l}\text { Median }[\mathrm{IQR}] \text { or } \\
\text { Number }(\%)\end{array}$ \\
\hline Concurrent Chemotherapy & $17(70.9 \%)$ \\
Yes & $7(29.2 \%)$ \\
No & \\
\hline
\end{tabular}

IQR interquartile range

apper $\mathrm{Gl}$ Adenocarcinoma $=$ adenocarcinomas of the gastroesophageal junction $(N=1)$, stomach $(N=1)$ and duodenum $(N=2)$

${ }^{b}$ Hepatobiliary Cancers $=$ intrahepatic cholangiocarcinoma $(N=2)$, extrahepatic cholangiocarcinoma $(N=1)$ and hepatocellular carcinoma $(N=1)$

'Other = pancreatic neuroendocrine tumor $(\mathrm{N}=1)$, Hodgkin Lymphoma treated with mantle and abdominal fields $(N=1)$

${ }^{\mathrm{d} O t h e r}=$ Mesenteric adenopathy, peritoneal nodules, aortocaval adenopathy

${ }^{\mathrm{e}}$ Reirradiation was given in twice daily fractions with a minimum $6 \mathrm{~h}$

interfraction interval

months (Fig. 2). Only palliative reirradiation intent was significantly associated with decreased OS (HR 3.38 95\% CI 1.24-9.03; $p=.018$ ).

Eight patients (33.3\%) were treated with palliative intent, five for palliation of bleeding, two for palliation of pain, and one for palliation of a tumor thrombus. Of these, only two patients (25\%) experienced noticeable palliation of the target symptoms.

\section{Toxicity}

Toxicity details are given in Table 3 . Thirteen patients (54\%) experienced acute side effects, although most were mild and consisted of G1-G2 symptoms including nausea, dyspepsia, diarrhea and esophagitis. One patient experienced G3 nausea and one experienced an acute G3 bleed due to an ulcer in the radiation field. The patient who experienced bleeding from the gastrojejunal anastomosis required a 4 day hospitalization and subsequent termination of the remaining scheduled radiation treatments. At the time radiation treatments were terminated, the patient had received 30 of a planned 39Gy, and the cumulative dose to the gastrojejunal anastomosis was 63Gy. This patient subsequently developed further bleeding from the gastrojejunal anastomosis qualifying as a grade 4 chronic toxicity two months after completion of reirradiation. The patient required endoscopic clips, epinephrine and coagulation and ultimate surgical revision of the gastrojejunostomy. One additional patient had their radiation treatment stopped early (also at 30 of a planned 39Gy) due to the development of a grade 2 duodenal ulcer which did not progress further. One additional patient developed severe GI symptoms found to be due to progression of peritoneal disease after they received 15 of a planned 39Gy. After discussion with the patient, their family and the multidisciplinary team, the remaining radiation treatments were cancelled and the patient went on to receive hospice care. All remaining patients completed the prescribed reirradiation course. 


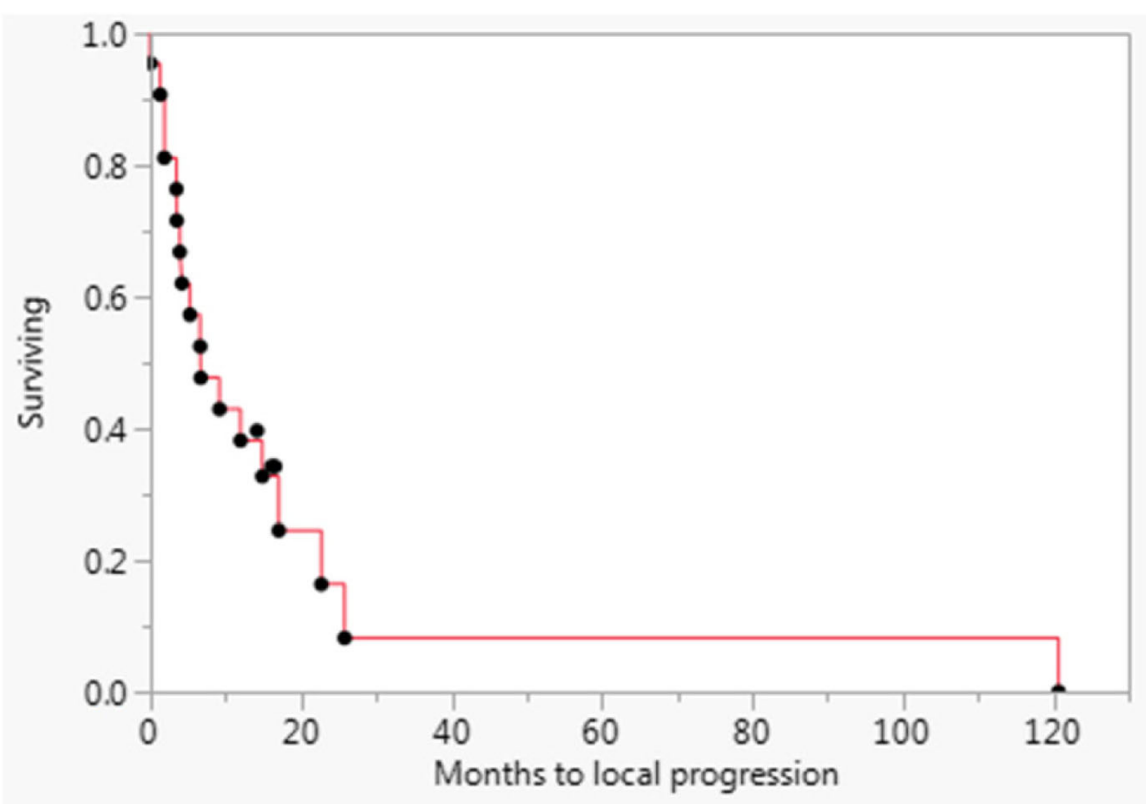

\begin{tabular}{rrrrrrr}
$\begin{array}{r}\text { Months to } \\
\text { progression }\end{array}$ & Survival & Failure & SurvStdErr & $\begin{array}{r}\text { Number } \\
\text { failed }\end{array}$ & $\begin{array}{r}\text { Number } \\
\text { censored }\end{array}$ & At Risk \\
\hline 0.000 & 1.0000 & 0.0000 & 0.0000 & 0 & 0 & 22 \\
0.000 & 0.9545 & 0.0455 & 0.0444 & 1 & 1 & 22 \\
1.300 & 0.9068 & 0.0932 & 0.0628 & 1 & 0 & 20 \\
1.830 & 0.8114 & 0.1886 & 0.0851 & 2 & 0 & 19 \\
3.430 & 0.7636 & 0.2364 & 0.0925 & 1 & 0 & 17 \\
3.470 & 0.7159 & 0.2841 & 0.0982 & 1 & 0 & 16 \\
3.900 & 0.6682 & 0.3318 & 0.1026 & 1 & 0 & 15 \\
4.170 & 0.6205 & 0.3795 & 0.1058 & 1 & 0 & 14 \\
5.230 & 0.5727 & 0.4273 & 0.1079 & 1 & 0 & 13 \\
6.600 & 0.5250 & 0.4750 & 0.1090 & 1 & 0 & 12 \\
6.670 & 0.4773 & 0.5227 & 0.1090 & 1 & 0 & 11 \\
9.170 & 0.4295 & 0.5705 & 0.1081 & 1 & 0 & 10 \\
11.970 & 0.3818 & 0.6182 & 0.1061 & 1 & 0 & 9 \\
14.170 & 0.3818 & 0.6182 & 0.1061 & 0 & 1 & 8 \\
14.870 & 0.3273 & 0.6727 & 0.1040 & 1 & 0 & 7 \\
16.070 & 0.3273 & 0.6727 & 0.1040 & 0 & 1 & 6 \\
16.530 & 0.3273 & 0.6727 & 0.1040 & 0 & 1 & 5 \\
17.070 & 0.2455 & 0.7545 & 0.1054 & 1 & 0 & 4 \\
22.700 & 0.1636 & 0.8364 & 0.0969 & 1 & 0 & 3 \\
25.830 & 0.0818 & 0.9182 & 0.0755 & 1 & 0 & 2 \\
120.700 & 0.0000 & 1.0000 & 0.0000 & 1 & 0 & 1
\end{tabular}

Fig. 1 Local progression-free survival for patients undergoing hyperfractionated accelerated reirradiation for abdominal malignancies

\section{Cumulative doses to luminal gastrointestinal organs}

Detailed dosimetric data sufficient for creating a composite radiation plan were available for 14 (58.3\%) patients in our cohort. For these patients, maximum doses to luminal gastrointestinal organs from the original, reirradiation and composite plans are given in
Table 4. Original, reirradiation and composite doses are given in both maximum nominal dose as well as maximum equivalent dose in 2 Gy fractions with an alpha beta ratio of $4\left(\mathrm{EQD}_{2}{ }^{4}\right)$. No significant relationships were found between maximum GI organ dose and G3+ toxicity. Figure 3 shows the original plan, the 
Table 2 Univariate analyses of factor associated with local progression-free survival and overall survival for patients receiving abdominal re-irradiation using a hyperfractionated regimen

\begin{tabular}{|c|c|c|c|c|c|c|}
\hline \multirow[b]{2}{*}{ Factor } & \multicolumn{3}{|c|}{ Local progression-free survival } & \multicolumn{3}{|c|}{ Overall survival } \\
\hline & Hazard ratio & 95\% Confidence interval & $P$-value & Hazard ratio & 95\% Confidence interval & $P$-value \\
\hline \multicolumn{7}{|l|}{ Age at Reirradiation } \\
\hline$<65$ & Reference & Reference & & Reference & Reference & \\
\hline$\geq 65$ & 0.72 & $0.27-1.89$ & .501 & 0.60 & $0.24-1.48$ & .268 \\
\hline \multicolumn{7}{|l|}{ Gender } \\
\hline Male & Reference & Reference & & Reference & Reference & \\
\hline Female & 0.87 & $0.27-2.54$ & .806 & 0.58 & $0.20-1.46$ & .256 \\
\hline \multicolumn{7}{|l|}{ Primary Cancer } \\
\hline Pancreatic Adeno & Reference & Reference & & Reference & Reference & \\
\hline Upper Gl Adeno ${ }^{\mathrm{a}}$ & 1.14 & $0.24-4.07$ & .856 & 1.36 & $0.20-4.60$ & .650 \\
\hline Colon Adeno & $1.12 \times 10^{-9 *}$ & $5.67 \times 10^{-55}-.35^{*}$ & $.002^{*}$ & 3.65 & $0.76-13.82$ & .098 \\
\hline Hepatobiliary ${ }^{\mathrm{b}}$ & 0.78 & $0.17-2.72$ & .715 & 1.02 & $0.23-3.44$ & .976 \\
\hline Other ${ }^{c}$ & 0.66 & $0.03-3.66$ & .678 & 2.34 & $0.34-9.95$ & .334 \\
\hline \multicolumn{7}{|l|}{ Initial RT dose } \\
\hline$\leq 45 \mathrm{~Gy}$ & Reference & Reference & & Reference & Reference & \\
\hline$>45 G y$ & 0.62 & $0.20-1.67$ & .361 & 1.09 & $0.41-2.69$ & .848 \\
\hline \multicolumn{7}{|c|}{ Interval between 1st and 2nd courses of RT } \\
\hline$<1$ year & Reference & Reference & & Reference & Reference & \\
\hline$\geq 1$ year & 1.19 & $0.12-3.28$ & .824 & 0.45 & $0.14-2.00$ & .261 \\
\hline \multicolumn{7}{|c|}{ Type of post-1st RT disease } \\
\hline New Primary & Reference & Reference & & Reference & Reference & \\
\hline Recurrence & 2.37 & $0.46-43.24$ & .351 & 0.50 & $0.16-2.22$ & .323 \\
\hline \multicolumn{7}{|l|}{ Reason for reirradiation } \\
\hline Definitive & Reference & Reference & & Reference & Reference & \\
\hline Palliative & 1.42 & $0.48-3.80$ & .510 & 3.38 & $1.24-9.03$ & .018 \\
\hline \multicolumn{7}{|l|}{ Reirradiation dose } \\
\hline$\leq 30 \mathrm{~Gy}$ & Reference & Reference & & Reference & Reference & \\
\hline$>30 \mathrm{~Gy}$ & 1.31 & $0.43-4.96$ & .650 & 1.10 & $0.44-3.13$ & .844 \\
\hline \multicolumn{7}{|l|}{ Reirradiation modality } \\
\hline 3DCRT & Reference & Reference & & Reference & Reference & \\
\hline IMRT & 0.62 & $0.21-1.64$ & .342 & 0.84 & $0.31-2.06$ & .708 \\
\hline \multicolumn{7}{|c|}{ Concurrent chemo with reirradiation? } \\
\hline No & Reference & Reference & & Reference & Reference & \\
\hline Yes & 1.51 & $0.51-5.55$ & .473 & 0.75 & $0.30-2.13$ & .565 \\
\hline
\end{tabular}

*Only colon adenocarcinoma primary type was significantly associated with increased LPFS, but the sample size was small ( $n=3$ ), with two patients not progressing and a third patient not progressing for 10 years

aupper Gl Adenocarcinoma = adenocarcinomas of the gastroesophageal junction $(N=1)$, stomach $(N=1)$ and duodenum $(N=2)$

${ }^{b}$ Hepatobiliary Cancers = intrahepatic cholangiocarcinoma $(N=2)$, extrahepatic cholangiocarcinoma $(N=1)$ and hepatocellular carcinoma $(N=1)$

${ }^{c}$ Other = pancreatic neuroendocrine tumor $(N=1)$, Hodgkin Lymphoma treated with mantle and abdominal fields $(N=1)$

reirradiation plan and the composite plan for the treatment of locally recurrent pancreatic adenocarcinoma.

\section{Discussion}

The results of this retrospective review performed at a high-volume tertiary referral cancer center show that hyperfractionated, accelerated reirradiation can be safely delivered with acceptable toxicity rates for patients with recurrent or new primary abdominal tumors who have received prior abdominal radiation. These data expand upon our previously reported experience of the initial 13 patients treated was published in 2009. While abdominal 


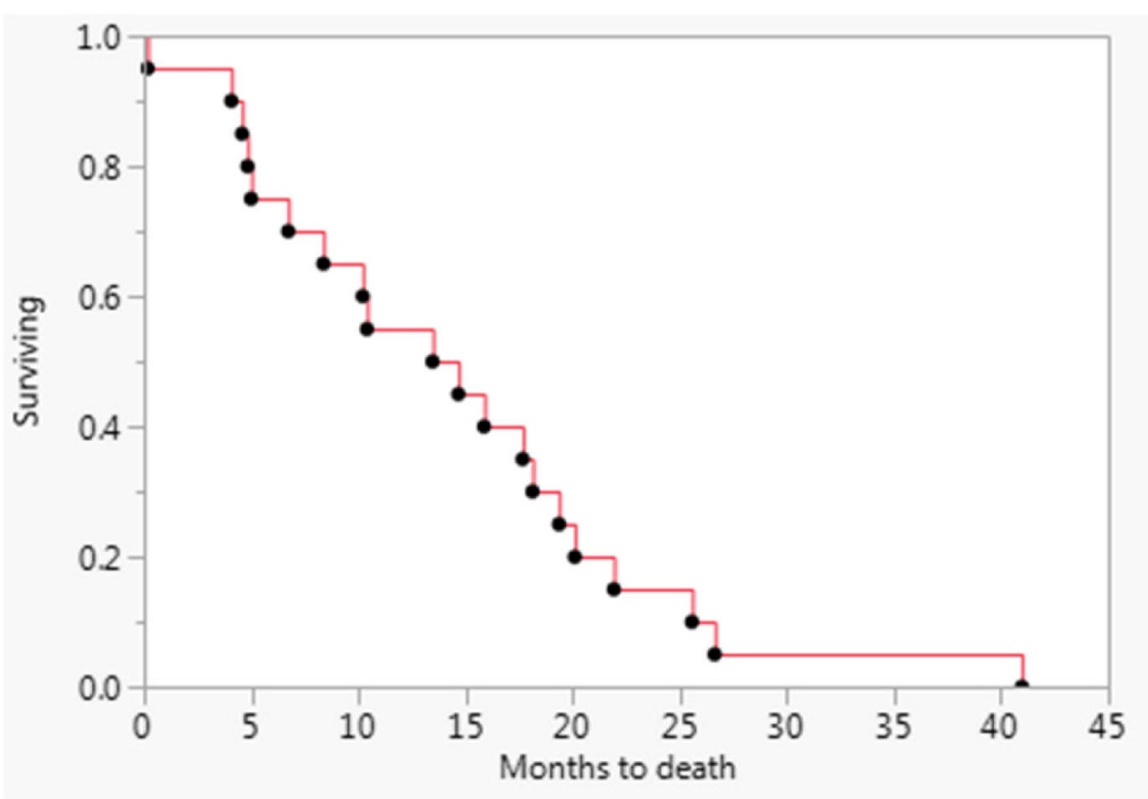

\begin{tabular}{|c|c|c|c|}
\hline $\begin{array}{r}\text { Months OS } \\
\text { after 2nd RT }\end{array}$ & Survival & Failure & SurvStdErr \\
\hline 0.0000 & 1.0000 & 0.0000 & 0.0000 \\
\hline 0.1700 & 0.9500 & 0.0500 & 0.0487 \\
\hline 4.0700 & 0.9000 & 0.1000 & 0.0671 \\
\hline 4.5700 & 0.8500 & 0.1500 & 0.0798 \\
\hline 4.8300 & 0.8000 & 0.2000 & 0.0894 \\
\hline 5.0000 & 0.7500 & 0.2500 & 0.0968 \\
\hline 6.7300 & 0.7000 & 0.3000 & 0.1025 \\
\hline 8.3700 & 0.6500 & 0.3500 & 0.1067 \\
\hline 10.2000 & 0.6000 & 0.4000 & 0.1095 \\
\hline 10.4000 & 0.5500 & 0.4500 & 0.1112 \\
\hline 13.4700 & 0.5000 & 0.5000 & 0.1118 \\
\hline 14.6700 & 0.4500 & 0.5500 & 0.1112 \\
\hline 15.8700 & 0.4000 & 0.6000 & 0.1095 \\
\hline 17.6700 & 0.3500 & 0.6500 & 0.1067 \\
\hline 18.1300 & 0.3000 & 0.7000 & 0.1025 \\
\hline 19.3700 & 0.2500 & 0.7500 & 0.0968 \\
\hline 20.1000 & 0.2000 & 0.8000 & 0.0894 \\
\hline 21.9300 & 0.1500 & 0.8500 & 0.0798 \\
\hline 25.5700 & 0.1000 & 0.9000 & 0.0671 \\
\hline 26.6300 & 0.0500 & 0.9500 & 0.0487 \\
\hline 40.9700 & 0.0000 & 1.0000 & 0.0000 \\
\hline
\end{tabular}

Number Number

failed censored At Risk

$0 \quad 0 \quad 20$

120

$\begin{array}{lll}1 & 0 & 19\end{array}$

$\begin{array}{lll}1 & 0 & 18\end{array}$

$\begin{array}{lll}1 & 0 & 17\end{array}$

$\begin{array}{lll}1 & 0 & 16\end{array}$

$\begin{array}{lll}1 & 0 & 15\end{array}$

$\begin{array}{lll}1 & 0 & 14\end{array}$

$\begin{array}{lll}1 & 0 & 13\end{array}$

110012

110011

$\begin{array}{lll}1 & 0 & 10\end{array}$

100

$1 \quad 0 \quad 8$

$\begin{array}{lll}1 & 0 & 7\end{array}$

$1 \quad 0 \quad 6$

$1 \quad 0 \quad 5$

$1 \quad 0 \quad 4$

103

$\begin{array}{lll}1 & 0 & 2\end{array}$

$1 \quad 0 \quad 1$

Fig. 2 Overall survival for patients undergoing hyperfractionated accelerated reirradiation for abdominal malignancies

reirradiation using this regimen was well tolerated, it appeared to have limited efficacy in terms of freedom from local progression and palliation of local symptoms.

In this cohort of patients, the 1-year LPFS was only $38 \%$, and the median [IQR] time to local progression was only 8 [3.8-19.2] months. Patients with colon adenocarcinoma seemed to have a longer LPFS; two patients never experienced local progression and a third patient not progressing until 10 years after reirradiation. However, this group of patients was small $(n=3)$, so it would not be prudent to draw definitive conclusions from these results. Patients in this cohort had a poor prognosis overall with a 1 -year OS of $50 \%$ and a median [IQR] overall survival of 14 [6.3-19.6] months. Patients 
Table 3 Acute Toxicities

\begin{tabular}{ll}
\hline Characteristic & Number (\%) \\
\hline $\begin{array}{l}\text { Patients Experiencing Acute Side Effects During } \\
\text { Reirradiation }\end{array}$ & $13(54 \%)$ \\
Acute RT Side Effects $^{\mathrm{a}}$ & \\
G1-2 Nausea & $10(41.7 \%)$ \\
G3 Nausea & $1(4.2 \%)$ \\
G1-2 Diarrhea & $1(4.2 \%)$ \\
Other G1-2 side effects & $3(12.5 \%)$ \\
G4 Gl bleed & $1(4.2 \%)$ \\
Patients Experiencing Acute 2nd RT Side Effects & $2(8.3 \%)$ \\
Acute RT Side Effects & \\
G3 Nausea & $1(4.2 \%)$ \\
G3 Pancreatitis and Biliary Sepsis & $1(4.2 \%)$ \\
\hline
\end{tabular}

${ }^{\text {a }}$ Some patients experienced more than one toxicity

treated with palliative intent had, predictably, a significantly worse overall survival, but this hyperfractionated, accelerated reirradiation regimen did not prove to be very effective in palliating symptoms of pain, bleeding or tumor thrombus. Only $25 \%$ of patients treated palliative reported noticeable symptom relief.

These modest results suggest alternative regimens should be explored to provide patients with better radiation therapy options in the abdominal reirradiation setting. Although the hyperfractionated schedule has the potential radiobiologic benefit of reducing the risks of late toxicities from cumulative radiation doses [36], particularly to sensitive luminal gastrointestinal structures, some groups have reported encouraging reports with a hypofractionated stereotactic body radiation therapy (SBRT) approach. The majority of published data come from studies reporting on reirradiation for pancreatic cancer using hypofractioned SBRT. Lomiska et al. utilized a regimen consisting of a median dose of 22.5Gy in 3 fractions to recurrent tumors of the pancreas and reported a median overall survival of only 5.9 months, but freedom from local progression was excellent at $85.7 \%$ (12 of 14 evaluable patients). Grade 3 or greater acute toxicities were reported in fewer than 10\% of patients [37]. Dagoglu et al. reported a median OS of 14 months, two year local control of $78 \%$ and G3 of greater acute toxicity rate of $10 \%$ in patients treated for unresectable locally recurrent pancreatic adenocarcinoma using a median of 25 Gy in a median of 5 fractions [38]. Wild et al. reported a median survival of 8.8 months in pancreatic adenocarcinoma patients reirradiated with SBRT using the same median SBRT dose of $25 \mathrm{~Gy}$ in 5 fractions. Rates of freedom from local progression at 6 and 12 months after SBRT reirradiation were 78 and $62 \%$, respectively. Effective symptom palliation (back or abdominal pain) was higher than in our series at $57 \%$. Only $28 \%$ of patients experienced acute toxicities, but no patient experienced G3 or greater acute toxicity. Analysis of this cohort also suggested that a progression-free interval of $>9$ months prior to isolated local recurrent or progression may predict for a greater benefit of SBRT reirradiation as their survival is more likely to be long enough for improved local control to be of meaningful benefit [39]. Most recently, Koong et al. showed that either single-fraction $(25 \mathrm{~Gy} \times 1)$ or five-fraction $(5-6.6 \mathrm{~Gy} \times 5)$ SBRT was effective in treating recurrent pancreatic cancer a median of 13 months after patients had received prior conventional radiotherapy. The median overall survival from reirradiation was 8.5 months, and the local failure rate was low at $19 \%$. Distant progression was a much more common pattern of failure at $64 \%$. Reirradiation was also well tolerated with this regimen, with only six $(26 \%)$ of patients experiencing either grade 2 or grade 3 toxicities, and four of these patients were treated with the single fraction SBRT regimen [40].

While our study demonstrated comparable overall survival rates, the prior studies using SBRT for reirradiation of pancreatic adenocarcinoma reported superior freedom from local progression. While our study included patients with gastrointestinal malignancies, the majority $(n=14$, $58.3 \%$ ) of patients included in this study were treated for pancreatic adenocarcinoma, and we would thus expect our one year freedom from local progression to be comparable if not higher. Furthermore, although our serious (G3 or greater) toxicity rate was low, our study reported an overall

Table 4 Initial Radiation, Reirradiation and Cumulative Maximum Dose to Bowel

\begin{tabular}{|c|c|c|c|c|c|c|}
\hline \multirow[t]{2}{*}{ Location } & \multicolumn{2}{|c|}{$\begin{array}{l}\text { Initial treatment dose in gray median } \\
\text { [range] mean } \pm S D\end{array}$} & \multicolumn{2}{|c|}{$\begin{array}{l}\text { Reirradiation treatment dose in } \\
\text { gray median [range] mean } \pm \mathrm{SD}\end{array}$} & \multicolumn{2}{|c|}{$\begin{array}{l}\text { Cumulative dose in gray median } \\
\text { [range] mean } \pm \mathrm{SD}\end{array}$} \\
\hline & Nominal dose & $\mathrm{EQD}_{2}^{4 \mathrm{a}}$ & Nominal dose & $\mathrm{EQD}_{2}^{4 \mathrm{a}}$ & Nominal dose & $\mathrm{EQD}_{2}^{4 a}$ \\
\hline Stomach & $\begin{array}{l}34.6[0-56.1] \\
35.9 \pm 15.1\end{array}$ & $\begin{array}{l}36.9[0-51.8] \\
35.7 \pm 14.5\end{array}$ & $\begin{array}{l}34.6[1.4-48] \\
30.0 \pm 14.2\end{array}$ & $\begin{array}{l}31.7[0.94-44.8] \\
27.4 \pm 13.5\end{array}$ & $\begin{array}{l}68.8[32-92.2] \\
65.9 \pm 15.3\end{array}$ & $\begin{array}{l}66[29.9-88.1] \\
63.1 \pm 15.2\end{array}$ \\
\hline Duodenum & $\begin{array}{l}40.5[21-55.7] \\
39.9 \pm 10.2\end{array}$ & $\begin{array}{l}43.9[16.3-55.5] \\
41.2 \pm 10.2\end{array}$ & $\begin{array}{l}39.2[0-48] \\
35.6 \pm 11.3\end{array}$ & $\begin{array}{l}35.7[0-44.8] \\
32.9 \pm 10.5\end{array}$ & $\begin{array}{l}75.7[50.4-95.4] \\
75.5 \pm 13.0\end{array}$ & $\begin{array}{l}76.3[46.0-89.8] \\
74.1 \pm 13.1\end{array}$ \\
\hline Small Bowel & $\begin{array}{l}39.6[20.7-52.8] \\
37.9 \pm 10.7\end{array}$ & $\begin{array}{l}42.2[16.2-52.3] \\
38.6 \pm 11.5\end{array}$ & $\begin{array}{l}35.6[0-48] \\
32.9 \pm 12.8\end{array}$ & $\begin{array}{l}31.9[0-44.8] \\
30.2 \pm 12.3\end{array}$ & $\begin{array}{l}71.4[50.4-95.4] \\
70.8 \pm 12.9\end{array}$ & $\begin{array}{l}67.9[46.1-89.8] \\
68.7 \pm 14.0\end{array}$ \\
\hline Large Bowel & $\begin{array}{l}36.1[20.9-52.8] \\
37.0 \pm 11.3\end{array}$ & $\begin{array}{l}38.4[16.3-51.7] \\
37.2 \pm 11.6\end{array}$ & $\begin{array}{l}35.9[0-48.1] \\
32.5 \pm 13.2\end{array}$ & $\begin{array}{l}32.1[0-44.8] \\
29.8 \pm 12.5\end{array}$ & $\begin{array}{l}68.1[50.4-98.1] \\
69.5 \pm 13.5\end{array}$ & $\begin{array}{l}66.4[46.1-93.1] \\
67.0 \pm 14.0\end{array}$ \\
\hline
\end{tabular}

${ }^{\mathrm{a}} \mathrm{EQD}_{2}{ }^{4}$ is the equivalent dose in two Gray fractions using an alpha beta ratio of 4 for late toxicity effects on the luminal abdominal $\mathrm{Gl}$ organs 


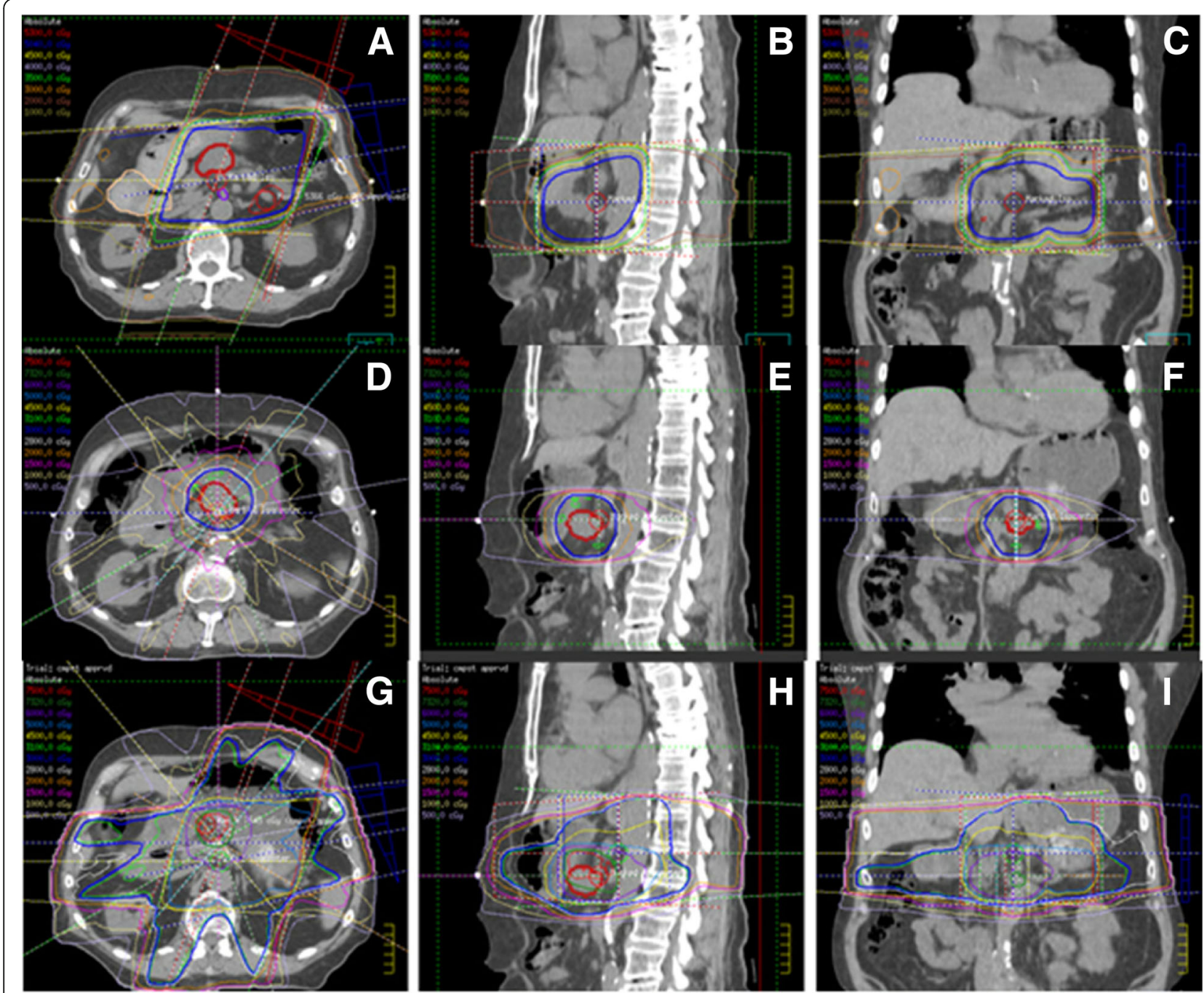

Fig. 3 A representative patient with pancreatic adenocarcinoma who was initially planned to receive 50.4Gy in 28 fractions using a 4-field 3D conformal radiation plan (a-c). Unfortunately, he only received 43.2Gy in 24 fractions before having to stop capecitabine-based chemoradiation due to a family emergency. He was subsequently unable to undergo surgical resection due to anatomic unresectability. Thirteen months later, he developed isolated local progression and was treated to a total dose of 30Gy in 20, twice-daily fractions of 1.5Gy each using an intensity-modulated radiation therapy technique (d-f). He received concurrent oral capecitabine chemotherapy. The cumulate plan is shown (g-i)

acute toxicity rate higher than those reported using SBRT, with a $54 \%$ acute toxicity rate in our study compared to 10 to $28 \%$ reported by the SBRT studies [37-40].

While this series represents the largest reported cohort of patients treated with hyperfractionated, accelerated abdominal reirradiation for recurrent or new primary abdominal malignancies, this study has several limitations that may limit its interpretation and broad applicability. The number of patients was relatively small, with only 24 patients treated over a 17 year period at a single institution. The cohort was relatively heterogeneous in terms of primary tumor type and prior treatment delivered. Additionally, acute toxicities were collected retrospectively based on hospital records and could have been underestimated.
Follow up was not standardized, varied between patients, and late toxicities may have been underreported as well.

\section{Conclusion}

In conclusion, although our study shows that hyperfractionated, accelerated abdominal reirradiation is well-tolerated, this regimen provides local control for a limited duration and has a modest palliative effect. Emerging data regarding SBRT reirradiation in the abdomen are promising, and may provide improved local control with similarly low toxicity rates. Further study is needed regarding the safety and efficacy of this modality of recurrent pancreatic adenocarcinoma as well as other abdominal malignancies. 


\section{Abbreviations}

3DCRT: Either 3D conformal radiation therapy; Cl: Confidence interval: CT: Computed tomography; CTCAE: Common Toxicity Criteria for Adverse Events; CTV: The clinical target volume; DM: Distant metastasis; FFLP: Freedom from local progression; Gl: Gastrointestinal; GTV: Gross tumor volume; Gy: Gray; HR: Hazard ratio; IMRT: Intensity-modulated radiation therapy; IQR: Interquartile range; LPFS: Local progression-free survival; LR: Local recurrences; OARs: Organsat-risk; OS: Overall survival; PTV: The planning target volume

\section{Availability of data and materials}

The datasets generated and/or analyzed during the current study are not publicly available as they were generated using patient health records, which are not public, but a de-identified master dataset is available on reasonable request with proper material transfer agreement in place with The University of Texas MD Anderson Cancer Center.

\section{Authors' contributions}

AH participated in data collection, data analysis and helped to draft the manuscript. EBH conceived of the study, assisted with data collection and data analysis and helped to draft the manuscript. PD helped in the design and coordination of the study. BDM, EJK, SK, JMH, CT, AK and GLS helped in the design of the study and manuscript revision. All authors read and approved the final manuscript.

\section{Ethics approval and consent to participate}

The University of Texas MD Anderson Cancer Center Institutional Review Board approval was obtained prior to collecting data for this study. The University of Texas MD Anderson Cancer Center Institutional Review Board awarded a waiver of informed consent due to the retrospective nature of this study.

\section{Consent for publication}

Not applicable.

\section{Competing interests}

The authors declare that they have no competing interests.

\section{Publisher's Note}

Springer Nature remains neutral with regard to jurisdictional claims in published maps and institutional affiliations.

\section{Author details}

${ }^{1}$ University of Texas Health San Antonio Long School of Medicine, San Antonio, TX, USA. ${ }^{2}$ The University of Texas MD Anderson Cancer Center, 1515 Holcombe Blvd Unit 97, Houston, TX 77030, USA.

Received: 8 March 2018 Accepted: 23 July 2018

Published online: 07 August 2018

\section{References}

1. Hishinuma S, Ogata Y, Tomikawa M, Ozawa I, Hirabayashi K, Igarashi S. Patterns of recurrence after curative resection of pancreatic cancer, based on autopsy findings. J Gastrointest Surg Off J Soc Surg Aliment Tract. 2006; 10:511-8.

2. Neoptolemos JP, Stocken DD, Friess H, Bassi C, Dunn JA, Hickey H, et al. A randomized trial of chemoradiotherapy and chemotherapy after resection of pancreatic cancer. N Engl J Med. 2004;350:1200-10.

3. Van Laethem J-L, Hammel P, Mornex F, Azria D, Van Tienhoven G, Vergauwe $P$, et al. Adjuvant gemcitabine alone versus gemcitabine-based chemoradiotherapy after curative resection for pancreatic cancer: a randomized EORTC-40013-22012/FFCD-9203/GERCOR phase II study. J Clin Oncol Off J Am Soc Clin Oncol. 2010;28:4450-6.

4. Spolverato G, Ejaz A, Kim Y, Squires MH, Poultsides GA, Fields RC, et al. Rates and patterns of recurrence after curative intent resection for gastric cancer: a United States multi-institutional analysis. J Am Coll Surg. 2014;219:664-75.

5. Shin $\mathrm{C}-\mathrm{H}$, Lee $\mathrm{W}-\mathrm{Y}$, Hong S-W, Chang $\mathrm{Y}-\mathrm{G}$. Characteristics of gastric cancer recurrence five or more years after curative gastrectomy. Chin J Cancer Res. 2016;28:503-10.

6. Harris GJC, Church JM, Senagore AJ, Lavery IC, Hull TL, Strong SA, et al. Factors affecting local recurrence of colonic adenocarcinoma. Dis Colon Rectum. 2002;45:1029-34.
7. National Comprehensive Cancer Network Guidelines Version 3.2017 Pancreatic Adenocarcinoma [Internet]. Available from: https://www.nccn. org/professionals/physician_gls/pdf/pancreatic.pdf. [cited 4 Jan 2018].

8. National Comprehensive Cancer Network Guidelines Version 5.2017 Gastric Cancer [Internet]. Available from: https://www.nccn.org/professionals/ physician_gls/pdf/gastric.pdf, [cited 4 Jan 2018]

9. NCCN. National Comprehensive Cancer Network Guidelines Version 2.2017 Colon Cancer [Internet]. Natl. Compr. Cancer Netw. Available from: https:// www.nccn.org/professionals/physician_gls/pdf/colon.pdf. [cited 11 Jul 2017]

10. National Comprehensive Cancer Network Guidelines- Hepatobiliary Cancers [Internet]. Available from: https://www.nccn.org/professionals/physician_gls/ pdf/hepatobiliary.pdf. [cited 2 Jan 2017]

11. Tanvetyanon T, Padhya T, McCaffrey J, Zhu W, Boulware D, Deconti R, et al. Prognostic factors for survival after salvage reirradiation of head and neck cancer. J Clin Oncol Off J Am Soc Clin Oncol. 2009;27:1983-91.

12. Sulman EP, Schwartz DL, Le TT, Ang KK, Morrison WH, Rosenthal Dl, et al. IMRT reirradiation of head and neck cancer-disease control and morbidity outcomes. Int J Radiat Oncol Biol Phys. 2009;73:399-409.

13. Takiar V, Garden AS, Ma D, Morrison WH, Edson M, Zafereo ME, et al. Reirradiation of head and neck cancers with intensity modulated radiation therapy: outcomes and analyses. Int J Radiat Oncol Biol Phys. 2016;95:1117-31.

14. Janot F, de Raucourt D, Benhamou E, Ferron C, Dolivet G, Bensadoun R-J, et al. Randomized trial of postoperative reirradiation combined with chemotherapy after salvage surgery compared with salvage surgery alone in head and neck carcinoma. J Clin Oncol Off J Am Soc Clin Oncol. 2008;26:5518-23.

15. Langer CJ, Harris J, Horwitz EM, Nicolaou N, Kies M, Curran W, et al. Phase II study of low-dose paclitaxel and cisplatin in combination with split-course concomitant twice-daily reirradiation in recurrent squamous cell carcinoma of the head and neck: results of radiation therapy oncology group protocol 9911. J Clin Oncol Off J Am Soc Clin Oncol. 2007;25:4800-5.

16. Henke G, Paulsen F, Steinbach JP, Ganswindt U, Isijanov H, Kortmann R-D, et al. Hypofractionated reirradiation for recurrent malignant glioma. Strahlenther Onkol Organ Dtsch Rontgengesellschaft Al. 2009;185:113-9.

17. Paulino AC, Mai WY, Chintagumpala M, Taher A, Teh BS. Radiation-induced malignant gliomas: is there a role for reirradiation? Int J Radiat Oncol Biol Phys. 2008;71:1381-7.

18. Fokas E, Wacker U, Gross MW, Henzel M, Encheva E, Engenhart-Cabillic R. Hypofractionated stereotactic reirradiation of recurrent glioblastomas : a beneficial treatment option after high-dose radiotherapy? Strahlenther Onkol Organ Dtsch Rontgengesellschaft Al. 2009;185:235-40.

19. Würschmidt F, Dahle J, Petersen C, Wenzel C, Kretschmer M, Bastian C. Reirradiation of recurrent breast cancer with and without concurrent chemotherapy. Radiat Oncol Lond Engl. 2008;3:28.

20. Cetingoz R, Arican-Alicikus Z, Nur-Demiral A, Durmak-Isman B, Bakis-Altas B, Kinay $M$. Is re-irradiation effective in symptomatic local recurrence of non small cell lung cancer patients? A single institution experience and review of the literature. J BUON Off J Balk Union Oncol. 2009;14:33-40.

21. Valentini V, Morganti AG, Gambacorta MA, Mohiuddin M, Doglietto GB, Coco C, et al. Preoperative hyperfractionated chemoradiation for locally recurrent rectal cancer in patients previously irradiated to the pelvis: a multicentric phase II study. Int J Radiat Oncol Biol Phys. 2006;64:1129-39.

22. Mohiuddin M, Lingareddy V, Rakinic J, Marks G. Reirradiation for rectal cancer and surgical resection after ultra high doses. Int J Radiat Oncol Biol Phys. 1993;27:1159-63.

23. Mohiuddin M, Marks GM, Lingareddy V, Marks J. Curative surgical resection following reirradiation for recurrent rectal cancer. Int J Radiat Oncol Biol Phys. 1997;39:643-9.

24. Mohiuddin M, Marks G, Marks J. Long-term results of reirradiation for patients with recurrent rectal carcinoma. Cancer. 2002;95:1144-50.

25. Lingareddy $\vee$, Ahmad NR, Mohiuddin M. Palliative reirradiation for recurrent rectal cancer. Int J Radiat Oncol Biol Phys. 1997;38:785-90.

26. Das P, Delclos ME, Skibber JM, Rodriguez-Bigas MA, Feig BW, Chang GJ, et al. Hyperfractionated accelerated radiotherapy for rectal cancer in patients with prior pelvic irradiation. Int J Radiat Oncol Biol Phys. 2010;77:60-5.

27. Tao R, Tsai CJ, Jensen G, Eng C, Kopetz S, Overman MJ, et al. Hyperfractionated accelerated reirradiation for rectal cancer: an analysis of outcomes and toxicity. Radiother Oncol J Eur Soc Ther Radiol Oncol. 2017;122:146-51.

28. Osborne EM, Eng C, Skibber JM, Rodriguez-Bigas MA, Chang GJ, Nancy You Y-Q, et al. Hyperfractionated Accelerated Reirradiation for Patients With Recurrent Anal Cancer Previously Treated With Definitive Chemoradiation. Am J Clin Oncol.2018;41(7):632-37. 
29. Haque W, Crane CH, Krishnan S, Delclos ME, Javle M, Garrett CR, et al. Reirradiation to the abdomen for gastrointestinal malignancies. Radiat Oncol Lond Engl. 2009;4:55.

30. Common Terminology Criteria for Adverse Events (CTCAE) Version 4 [Internet]. 2009. Available from: https://www.eortc.be/services/doc/ctc/ CTCAE_4.03_2010-06-14_QuickReference_5x7.pdf. [cited 4 Jan 2018]

31. Elhammali A, Patel M, Weinberg B, Verma V, Liu J, Olsen JR, et al. Late gastrointestinal tissue effects after hypofractionated radiation therapy of the pancreas. Radiat Oncol Lond Engl. 2015;10:186.

32. Dische S, Saunders MI, Sealy R, Werner ID, Verma N, Foy C, et al. Carcinoma of the cervix and the use of hyperbaric oxygen with radiotherapy: a report of a randomised controlled trial. Radiother Oncol J Eur Soc Ther Radiol Oncol. 1999;53:93-8.

33. Deore SM, Shrivastava SK, Supe SJ, Viswanathan PS, Dinshaw KA. Alpha/beta value and importance of dose per fraction for the late rectal and rectosigmoid complications. Strahlenther Onkol Organ Dtsch Rontgengesellschaft Al. 1993;169:521-6.

34. Holyoake DLP, Aznar M, Mukherjee S, Partridge M, Hawkins MA. Modelling duodenum radiotherapy toxicity using cohort dose-volume-histogram data. Radiother Oncol J Eur Soc Ther Radiol Oncol. 2017;123:431-7.

35. Kaplan E, Meier P. Nonparametric estimation from incomplete observations. J Am Stat Associ. 1958;53:457-81.

36. Cox JD, Guse C, Asbell S, Rubin P, Sause WT. Tolerance of pelvic normal tissues to hyperfractionated radiation therapy: results of protocol 83-08 of the radiation therapy oncology group. Int J Radiat Oncol Biol Phys. 1988;15: $1331-6$.

37. Lominska CE, Unger K, Nasr NM, Haddad N, Gagnon G. Stereotactic body radiation therapy for reirradiation of localized adenocarcinoma of the pancreas. Radiat Oncol Lond Engl. 2012;7:74.

38. Dagoglu N, Callery M, Moser J, Tseng J, Kent T, Bullock A, et al. Stereotactic body radiotherapy (SBRT) Reirradiation for recurrent pancreas Cancer. J Cancer. 2016;7:283-8.

39. Wild AT, Hiniker SM, Chang DT, Tran PT, Khashab MA, Limaye MR, et al. Re-irradiation with stereotactic body radiation therapy as a novel treatment option for isolated local recurrence of pancreatic cancer after multimodality therapy: experience from two institutions. J Gastrointest Oncol. 2013;4:343-51.

40. Koong AJ, Toesca DAS, von Eyben R, Pollom EL, Chang DT. Reirradiation with stereotactic body radiation therapy after prior conventional fractionation radiation for locally recurrent pancreatic adenocarcinoma. Adv Radiat Oncol. 2017;2:27-36

Ready to submit your research? Choose BMC and benefit from:

- fast, convenient online submission

- thorough peer review by experienced researchers in your field

- rapid publication on acceptance

- support for research data, including large and complex data types

- gold Open Access which fosters wider collaboration and increased citations

- maximum visibility for your research: over $100 \mathrm{M}$ website views per year

At BMC, research is always in progress.

Learn more biomedcentral.com/submissions 